\title{
RESPON IMPLEMENTASI BAHAN AJAR DIGITAL “流利说汉语” [liúlì shū hànyŭ] PADA PEMBELAJARAN BAHASA MANDARIN KELAS X DI SMAN 2 MALANG
}

\author{
Aiga Ventivani \\ Universitas Negeri Malang \\ aiga.ventivani.fs@um.ac.id \\ Lukluk Ul Muyassaroh \\ Universitas Negeri Malang \\ Luklukul03@gmail.com \\ Octi Rjeky Mardasari \\ Universitas Negeri Malang \\ octi.rjeky.fs@um.ac.id
}

\begin{abstract}
This study was conducted to determine the response to the implementation of the Chinese digital teaching material “流利说汉语” [liúlì shuō hànyǔ]. The type of research used in this research is qualitative research. This study uses a supporting instrument in the form of an open questionnaire distributed via google form. The data sources of this research are Mandarin language teachers and X-grade high school students across SMAN 2 Malang. The data in this study are the results of an open questionnaire filled out by the Chinese language teacher and high school students in class X. The results of this study are the responses of students and Chinese teachers to the implementation of digital teaching materials “流利说 汉语” [liúlì shuō hànyǔ] on learning Mandarin got a positive response. There are suggestions given by researchers so that the use of digital teaching materials can be used optimally. The teaching materials are better used using the internet network to be able to operate the video in it. The next suggestion is for further developers to be able to develop similar teaching materials that can be used offline and other materials that are by following the applicable curriculum.
\end{abstract}

Keywords: Mandarin, digital teaching materials, $1^{\text {st }}$ grade high school

\begin{abstract}
ABSTRAK
Penelitian ini dilakukan untuk mengetahui respon implementasi bahan ajar digital Bahasa Mandarin “流 利说汉语” [liúlì shuo hànyǔ]. Jenis penelitian yang digunakan dalam penelitian ini adalah penelitian kualitatif. Penelitian ini menggunakan instrumen pendukung berupa lembar angket terbuka yang disebar melalui google form. Sumber data penelitian ini adalah guru pengampu mata pelajaran Bahasa Mandarin dan siswa SMA kelas X lintas minat SMAN 2 Malang. Data dalam penelitian ini merupakan hasil lembar angket terbuka yang diisi oleh guru pengampu mata pelajaran Bahasa Mandarin dan siswa SMA kelas X. Hasil dari penelitian ini yaitu respon siswa dan guru Bahasa Mandarin terhadap implementasi bahan ajar digital “流利说汉语” [liúlì shuō hànyǔ]pada pembelajaran Bahasa Mandarin mendapatkan respon positif. Terdapat saran yang diberikan oleh peneliti agar penggunaan bahan ajar digital tersebut dapat digunakan secara maksimal. Bahan ajar tersebut lebih baik digunakan mengunakan jaringan internet agar dapat mengoperasikan video didalamnya, Saran selanjutnya yaitu untuk pengembang selanjutnya agar dapat mengembangkan bahan ajar sejenis yang dapat digunakan secara offline dan materi lainnya yang sesuai dengan Kurikulum yang berlaku.
\end{abstract}

Kata kunci: Bahasa Mandarin, bahan ajar digital, SMA kelas X 


\section{PENDAHULUAN}

Bahasa Mandarin mengalami perkembangan yang sangat pesat seiring dengan berkembangnya Negara China di berbagai bidang. Perkembangan bahasa Mandarin juga dirasakan di Indonesia. Belajar bahasa Mandarin saat ini banyak diminati masyarakat Indonesia sehingga semakin banyak pula lembaga pendidikan formal atau non formal yang menyediakan pelajaran bahasa Mandarin terutama pada pendidikan formal. Di kota Malang terdapat sepuluh sekolah menengah atas negeri. Begitu pula dengan sekolah swasta, banyak sekolah yang telah mengajarkan bahasa Mandarin sebagai pelajaran bahasa Asing, baik dari jenjang sekolah dasar hingga jenjang sekolah menengah atas.

Pada observasi awal ditemukan bahwa saat ini telah banyak sekolah yang mengajarkan bahasa Mandarin, namun masih banyak pula yang menggunakan handout atau modul yang berbentuk kertas (fisik). Hal tersebut berbanding terbalik dengan perkembangan pendidikan saat ini yang telah berjalan beriringan dengan perkembangan teknologi. Pendidikan abad 21 memiliki tantangan sekaligus peluang bagi lembaga pendidikan. Syarat maju dan berkembang lembaga pendidikan harus memiliki daya inovasi dan dapat berkolaborasi terutama menggunakan IPTEK. Terlebih lagi pada masa pandemi Covid 19 yang mengharuskan pembelajaran dilakukan secara daring sampai batas waktu yang tidak ditentukan. Untuk mendukung proses pembelajaran daring, maka diperlukan bahan ajar yang sesuai.

Pada penelitian Baroroh (2013: 31) menyebutkan bahwa salah satu faktor yang mempengaruhi kualitas hasil pembelajaran adalah interaksi antara peserta didik dengan guru dan bahan ajar. Sementara itu, Prastowo (2012: 301) menjabarkan manfaat bahan ajar dibedakan menjadi dua macam, yaitu manfaat bagi guru dan siswa. Manfaat yang diperoleh oleh guru yaitu bahan ajar sesuai dengan tuntutan kurikulum, tidak tergantung dengan buku teks dan buku paket bantuan pemerintah, sedangkan manfaat yang diperoleh peserta didik yaitu, menciptakan pembelajaran menarik, menumbuhkan motivasi, mengurangi ketergantungan dan mendapatkan kemudahan dalam mempelajari setiap indikator yang terdapat pada perangkat pembelajaran yang disusun oleh guru. Dengan demikian, dapat disimpulkan bahwa penggunaan bahan ajar yang sesuai dalam proses pembelajaran sangat diperlukan.

Selain ditemukan bahwa guru kesulitan menemukan bahan ajar yang sesuai untuk pembelajaran daring, pada observasi awal juga ditemukan masalah bahwa guru kesulitan menemukan bahan ajar Bahasa Mandarin yang sesuai dengan kurikulum. Hal tersebut sesuai dengan penelitian Haryanti (2013: 655) yang menyebutkan bahwa buku ajar bahasa Mandarin yang berbahasa Indonesia masih sangat sedikit sehingga menyulitkan proses transfer ilmu sehinga para guru masih menggunakan bahan ajar bahasa Mandarin terbitan Tiongkok. Senada dengan Haryanti, hasil penelitian Mardasari (2019: 41) yang menunjukkan bahwa salah satu bahan ajar bahasa Mandarin yang banyak digunakan di SMA Kota Malang tidak sesuai dengan silabus bahasa Mandarin yang terdapat dalam Kurikulm 2013. 韩明 [Han Ming] (2012) menemukan bahwa sebagian besar buku teks bahasa Mandarin yang digunakan di Asia Tenggara adalah buku teks yang ditulis oleh universitas-universitas Tiongkok.

Abidin (2016:263) menyatakan bahwa bahan ajar adalah seperangkat materi yang disusun oleh guru untuk mengembangkan pengetahuan, keterampilan, dan sikap positif terhadap pembelajaran dari kurikulum yang berlaku. Azis (2019: 33) membedakan jenis bahan ajar 
menjadi dua, yaitu bahan ajar cetak dan non cetak. Prastowo (2012) menyebutkan bahwa bahan ajar non cetak adalah perangkat bahan ajar yang memuat materi atau isi pelajaran untuk mencapai tujuan pembelajaran yang dituangkan dengan menggunakan teknologi non cetak. Nafidah \& Suratman (2021) bahan ajar digital adalah bahan ajar yang memanfaatkan kombinasi audio, video, komputer, atau alat elektronik lainnya. Berdasarkan pengertian tersebut, bahan ajar digital “流利说汉语” [liúlì shuō hànyǔ] merupakan bahan ajar non cetak yang telah dikembangkan sesuai dengan kurikulum 2013 bahasa Mandarin yang berlaku serta berbentuk digital.

Kelebihan bahan ajar digital menurut Erviana (2017) dibagi menjadi tiga, yaitu kegunaan (usability), kemudahan baca (readability) dan kemudahan penggunaan (ease of use). Bahan ajar digital berfungsi untuk memberikan kemudahan pada pembaca dengan memberikan penampilan yang lebih menarik karena terdapat audio, video, dan animasi yang dapat mempermudah proses penyampaian informasi dan dapat meningkatkan pemahaman siswa. Bahan ajar digital dapat membantu guru dan peserta didik dalam proses pembelajaran, karena dengan adanya bahan ajar digital tidak perlu membeli buku cetak sehingga dapat memberikan efisiensi dari segi waktu dan biaya. Penggunaan bahan ajar yang efisien bertujuan untuk mencapai tujuan pembelajaran yang telah ditetapkan pada struktur kurikulum Bahasa Mandarin.

Struktur kurikulum SMA yang berlaku pada saat ini adalah struktur kurikulum 2013. Pada kurikulum 2013, kompetensi inti dan kompetensi dasar bahasa Mandarin termasuk dalam kelompok peminatan ilmu bahasa dan sastra asing (kurikulum 2013, 2012: 156). Fadlillah (2014:16) mengatakan bahwa implementasi Kurikulum 2013 diharapkan mampu mencetak peserta didik yang memiliki kompetensi sikap, keterampilan, dan pengetahuan yang meningkat dan berkembang sesuai dengan jenjang pendidikan yang telah ditempuh sehingga dapat berpengaruh dan menentukan kesuksesan dalam hidup di masa depan. Dalam silabus bahasa Mandarin kelas X dalam paparan materi disebutkan topik untuk kelas X terdiri dari salam, sapaan, perkenalan jati diri, kegiatan di sekolah, keadaan di dalam kelas dan kegiatan belajar mengajar. Pada penelitian ini tim peneliti ingin mengetahui respon implementasi bahan ajar digital bahasa Mandarin kelas X materi个人信息 dari pengguna bahan ajar tersebut.

Chaplin (2011) menyebutkan bahwa response adalah sebarang proses otot atau kelenjar yang dimunculkan oleh satu perangsang ataupun salah satu jawaban. Jawaban tersebut merupakan jawaban dari pertanyaan kuesioner atau dapat dikatakan sebagai tingkah laku yang terlihat jelas maupun tersembunyi. Sementara itu, Husna (2018) menyatakan bahwa sikap yang muncul dapat positif yakni cenderung menyenangi, mendekati dan mengharapkan suatu objek, seseorang disebut mempunyai respon positif dilihat dari tahap kognisi, afeksi, dan psikomotorik. Lebih lanjut Husna (2018) juga menjelaskan bahwa seseorang mempunyai respon negatif apabila informasi yang didengarkan atau perubahan suatu objek tidak mempengaruhi tindakan atau malah menghindar dan membenci objek tertentu.

\section{METODE}

Penelitian ini merupakan jenis penelitian kualitatif. Peneliti ingin menggali lebih dalam mengenai informasi tentang respon siswa dan respon guru tentang implementasi bahan ajar digital “流利说汉语” [liúlì shuō hànyǔ] pada pembelajaran Bahasa Mandarin kelas X di SMAN 
2 Malang. Pada penelitian ini, peneliti sebagai instrumen utama yang menggunaan instrumen pendukung yaitu lembar angket terbuka yang diberikan setelah pembelajaran menggunakan bahan ajar digital “流利说汉语” [liúlì shuō hànyǔ]. Peneliti memilih angket terbuka agar narasumber dapat menjawab lebih leluasa pertanyaan yang diajukan. Sumber data penelitian ini adalah siswa kelas $X$ lintas minat SMA Negeri 2 Malang sebanyak tiga puluh tiga siswa dan guru Bahasa Mandarin. Data penelitian ini yaitu jawaban yang diperoleh dari lembar angket terbuka yang ditulis oleh narasumber. Setelah informasi yang diperlukan terkumpul, langkah selanjutnya yaitu peneliti melakukan analisis data menggunakan analisis Miles and Hubermen (dalam Barsowi dan Suwandi, 2008). Terdapat tiga tahap yang dilakukan oleh peneliti pada tahap analisis. Pertama peneliti mengklasifikasikan data, kemudian menyajikan data, tahap terakhir yaitu menarik kesimpulan dari data tersebut.

\section{HASIL DAN PEMBAHASAN}

Penerapan bahan ajar digital “流利说汉语”dilaksanakan di kelas X lintas minat SMA Negeri 2 Malang, tanggal 23 Agustus 2021 pukul 10.00 -11.30 WIB pada pembelajaran Bahasa Mandarin. Siswa yang hadir sebanyak 35 siswa. Selain itu, peneliti juga menjaring informasi dari guru pengampu mata pelajaran Bahasa Mandarin. Angket yang digunakan merupakan angket terbuka sehingga narasumber lebih leluasa memberikan informasi yang diperlukan peneliti. Angket tersebut berbasis google form sehingga pengumpulan informasi dapat dilakukan secara daring. Berikut hasil dari angket tersebut.

Tabel 1. hasil angket guru pengampu Bahasa Mandarin

\begin{tabular}{|c|c|c|c|}
\hline NO. & $\begin{array}{l}\text { Pertanyaan pada lembar angket } \\
\text { terbuka }\end{array}$ & Jawaban & Alasan \\
\hline 1. & $\begin{array}{l}\text { Apakah Anda menyukai bahan } \\
\text { ajar digital Bahasa Mandarin } \\
\text { 流利说汉语[liúlì shū hànyǔ] } \\
\text { atau tidak? }\end{array}$ & Suka & $\begin{array}{l}\text { 1. memudahkan saat pembelajaran } \\
\text { daring } \\
\text { 2. dikemas dengan sederhana sehingga } \\
\text { mudah mengaksesnya } \\
\text { 3. Buku digital ini memiliki fitur-fitur } \\
\text { yang mendukung materi } \\
\text { 4. Dikemas sangat menarik dan } \\
\text { menyenangkan sekali }\end{array}$ \\
\hline 2. & $\begin{array}{l}\text { Apakah bahan ajar digital } \\
\text { Bahasa Mandarin 流利说汉语 } \\
\text { [liúli shuō hànyǔ] membantu } \\
\text { Anda dalam memberikan } \\
\text { materi Bahasa Mandarin? }\end{array}$ & $\mathrm{Ya}$ & $\begin{array}{l}\text { 1. efektif dan tidak ribet. } \\
\text { 2. sangat mempermudah siswa dalam } \\
\text { belajar. bisa di akses secara mudah } \\
\text { kapan saja. } \\
\text { 3. buku digital ini terdapat banyak } \\
\text { sekali fitur yang mendukung materi }\end{array}$ \\
\hline 3. & $\begin{array}{l}\text { Apakah bahan ajar digital } \\
\text { Bahasa Mandarin 流利说汉语 } \\
\text { [liúli shuō hànyǔ] mudah } \\
\text { dioperasikan? }\end{array}$ & mudah dioperasikan. & $\begin{array}{l}\text { 1.bahan ajar tersebut sangat mudah } \\
\text { dioperasikan menyesuaikan } \\
\text { kemajuan zaman } \\
\text { 2.mudah dioperasikan dan terdapat } \\
\text { petunjuk2 yang dapat dipahami } \\
\text { pengguna } \\
\text { 3. karena menggunakan aplikasi yang } \\
\text { mudah untuk diakses }\end{array}$ \\
\hline
\end{tabular}




\section{JURNAL ILMIAH BAHASA DAN SASTRA}

Volume 8 Nomor 2 Tahun 2021

eISSN : 25494155 - pISSN : 23557083

\begin{tabular}{|l|l|l|l|}
\hline 4. & $\begin{array}{l}\text { Apakah materi yang terdapat } \\
\text { dalam bahan ajar digital }\end{array}$ & Jelas. & $\begin{array}{l}\text { 1.sudah jelas karena menggunakan } \\
\text { bahasa yang gampang dimengerti }\end{array}$ \\
& $\begin{array}{l}\text { Bahasa Mandarin 流利说汉语 } \\
\text { [liúlì shuō hànyǔ] sudah jelas? }\end{array}$ & & $\begin{array}{l}\text { 2.dengan ada soal didalamnya, siswa } \\
\text { dapat berlatih sehingga dapat } \\
\text { mengerti }\end{array}$ \\
& $\begin{array}{l}\text { 3.Materi yang disajikan tersusun } \\
\text { secara sistematis. }\end{array}$ \\
\hline
\end{tabular}

Berdasarkan hasil angket terbuka yang diperoleh, guru Bahasa Mandarin merasa terbantu dengan adanya bahan ajar digital “流利说汉语” [liúlì shuō hànyǔ]. Guru pengampu Bahasa Mandarin menyukai bahan ajar digital ini karena memudahkan saat pembelajaran daring, dikemas dengan sederhana dan memudahkan mengaksesnya, serta memiliki fitur-fitur yang mendukung materi dan dikemas sangat menarik. Darmawan (2015) bahwa media informasi dan Teknologi (IT) dapat mempermudah dan mempercepat proses pembelajaran. Selain itu, guru Bahasa Mandarin merasa bahwa bahan ajar digital ini membantu dalam memberikan materi Bahasa Mandarin. Hal tersebut sesuai dengan pernyataan Erviana (2017) tentang kelebihan bahan ajar yaitu kelebihan kegunaan (usability) yaitu bahan ajar digital berfungsi untuk menyampaikan informasi atau ilmu pengetahuan kepada pembaca yang dapat digunakan kapan saja, baik saat proses pembelajaran atau diluar proses pembelajaran.

Guru pengampu Bahasa Mandarin juga merasa bahan ajar digital Bahasa Mandarin 流利 说汉语[liúlì shuō hànyǔ] tersebut mudah dioperasikan dan praktis. Bahan ajar tersebut dirasa sangat mudah dioperasikan karena disusun menggunakan teknologi yang menyesuaikan kemajuan zaman, terdapat petunjuk-petunjuk yang dapat dipahami pengguna, dan menggunakan aplikasi yang mudah untuk diakses. Bahan ajar ini dianggap efektif dan tidak ribet sehingga sangat mempermudah siswa dalam belajar dan bisa di akses secara mudah kapan saja. Hal tersebut senada dengan pendapat Alperi (2019:103) tentang kelebihan teknologi digital antara lain biaya murah, tidak tergantung jarak, memungkinkan pengenalan layananlayanan baru, kapasitas besar, fleksibilitas keuntungan, lebih mudah diakses, dan efisiensi waktu.

Guru menganggap bahwa materi yang terdapat dalam bahan ajar digital Bahasa Mandarin 流利说汉语[liúlì shuō hànyǔ] sudah jelas. Hal tersebut diungkapkan oleh guru Bahasa Mandarin karena bahan ajar digital Bahasa Mandarin 流利说汉语 [liúlì shuo hànyǔ] menggunakan bahasa yang gampang dimengerti, materi yang disajikan tersusun secara sistematis., serta dengan ada soal didalamnya dapat membantu untuk memberi latihan siswa sehingga dapat mengerti. Hal tersebut sesuai dengan pendapat Erviana (2017) tentang kelebihan bahan ajar yaitu kemudahan baca (readability) dan kemudahan penggunaan (ease of use).

Tabel 2. hasil angket siswa:

\begin{tabular}{|l|l|l|l|}
\hline NO. & $\begin{array}{l}\text { Pertanyaan pada lembar } \\
\text { angket terbuka }\end{array}$ & Jawaban & Alasan \\
\hline 1. & $\begin{array}{l}\text { Apakah Anda menyukai } \\
\text { bahan ajar digital Bahasa }\end{array}$ & Suka & $\begin{array}{l}\text { 1.Materi sangat jelas } \\
\text { 2.Mudah digunakan tanpa perlu membawa } \\
\text { secara fisik }\end{array}$ \\
& $\begin{array}{l}\text { Mandarin 流 利 说 汉 语 } \\
\text { [liúlì shuō hànyŭ] atau }\end{array}$ & & 3.sangat menarik karena terdapat gambar \\
\hline
\end{tabular}




\begin{tabular}{|c|c|c|c|}
\hline & tidak? & & $\begin{array}{l}\text { dan soal yang membantu dalam belajar } \\
\text { 4.Tidak hanya menarik tetapi membuat } \\
\text { saya semakin ingin mempelajari lebih } \\
\text { dalam tentang bahasa mandarin }\end{array}$ \\
\hline 2. & $\begin{array}{l}\text { Apakah tampilan bahan } \\
\text { ajar digital Bahasa } \\
\text { Mandarin 流利 说 汉 语 } \\
\text { [liúli shuo hànyǔ] menarik } \\
\text { untuk membuat Anda } \\
\text { belajar Bahasa Mandarin? }\end{array}$ & menarik. & $\begin{array}{l}\text { 1. sangat menarik karena didalam bahan } \\
\text { ajar tersebut terdapat gambar-gambar } \\
\text { yang membuat para pembaca tidak } \\
\text { bosan } \\
\text { 2. Terdapat hiasan perpaduan hiasan } \\
\text { Indonesia dan Tiongkok, tulisan bahan } \\
\text { ajar juga jelas } \\
\text { 3.materi yang dijabarkan dalam buku ini } \\
\text { singkat padat dan jelas } \\
\text { 4. Diliat dari gambar animasi yang } \\
\text { mendukung serta warna yang cerah. }\end{array}$ \\
\hline 3. & $\begin{array}{l}\text { Apakah bahan ajar digital } \\
\text { Bahasa Mandarin 流利说 } \\
\text { 汉 语 [liúlì shuō hànyǔ] } \\
\text { mudah dioperasikan? }\end{array}$ & mudah dioperasikan. & $\begin{array}{l}\text { 1.bahan ajar tersebut sangat mudah di } \\
\text { operasikan, selain itu saat membuka } \\
\text { link youtube juga sangat mudah } \\
\text { 2.mudah dioperasikan di layar genggam } \\
\text { atau laptop } \\
\text { 3.karena masih menggunakan aplikasi } \\
\text { yang mudah untuk diakses } \\
\text { 4.menyesuaikan kemajuan zaman. }\end{array}$ \\
\hline 4. & $\begin{array}{l}\text { Apakah materi yang } \\
\text { terdapat dalam bahan ajar } \\
\text { digital Bahasa Mandarin } \\
\text { 流利 说 汉 语 [liúli shuō } \\
\text { hànyǔ] sudah jelas? }\end{array}$ & Jelas. & $\begin{array}{l}\text { 1.materi dibahas secara detail, selain itu } \\
\text { adanya yufa yang sangat memudahkan } \\
\text { pembaca untuk mempelajarinya } \\
\text { 2.terdapat contoh suara dan gambar juga } \\
\text { tidak buram } \\
\text { 3. sudah sangat jelas dan terjabar. }\end{array}$ \\
\hline 5. & 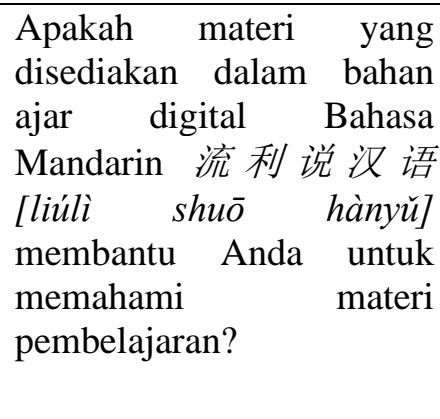 & Ya, membantu. & $\begin{array}{l}\text { 1.sangat membantu karena penjelasan } \\
\text { materinya sangat bagus dan mudah } \\
\text { dipahami } \\
\text { 2.materi yang komplit } \\
\text { 3.didalamnya terdapat fitur video atau } \\
\text { suara yg semakin memperjelas materi } \\
\text { 4.Baik dari keterampilan menyimak, } \\
\text { membaca, berbicara, menulis lengkap } \\
\text { tersaji dalam bahan ajat digital ini. }\end{array}$ \\
\hline 6. & $\begin{array}{l}\text { Bagian apa yang paling } \\
\text { Anda suka dari bahan ajar } \\
\text { digital Bahasa Mandarin } \\
\text { 流利 说 汉语 [liúli shuō } \\
\text { hànyǔ] tersebut? }\end{array}$ & & $\begin{array}{l}\text { 1. Materinya yang sangat jelas dan adanya } \\
\text { link youtube, karena saat ini masih } \\
\text { jarang sekali ada bahan ajar yang } \\
\text { seperti itu } \\
\text { 2. Terdapat tutorial step by step penulisan } \\
\text { hanzi } \\
\text { 3. Bagian penjelasan melalui voice note } \\
\text { yg terdapat dalam buku karena semakin } \\
\text { memperjelas materi yg ada }\end{array}$ \\
\hline
\end{tabular}




\section{JURNAL ILMIAH BAHASA DAN SASTRA}

Volume 8 Nomor 2 Tahun 2021

eISSN : 25494155 - pISSN : 23557083

4.Langsung dapat akses ke sumber materi seperti akses ke yuotube maupun kesumber yang digunakan dalam bahan ajar tersebut.

Berdasarkan hasil angket siswa yang telah dianalisis, maka dapat diperoleh informasi bahwa siswa menyukai bahan ajar digital Bahasa Mandarin 流利说汉语[liúlì shūo hànyǔ]. Darmawan (2015) mengungkapkan bahwa media informasi dan Teknologi (IT) dapat mempermudah dan mempercepat proses pembelajaran. Hal tersebut sesuai dengan alasan siswa menyukai bahan ajar tersebut diantaranya karena siswa merasa materi dalam bahan ajar digital Bahasa Mandarin 流利说汉语[liúlì shuō hànyǔ] sangat jelas, mudah digunakan tanpa perlu membawa secara fisik, sangat menarik karena terdapat gambar dan soal yang membantu dalam belajar, bahkan membuat siswa semakin ingin mempelajari lebih dalam tentang bahasa Mandarin.

Gambar-gambar, animasi, hiasan yang memadukan antara Indonesia dan Tiongkok, ukuran tulisan yang jelas, penjelasan materi yang padat dan jelas, serta pemilihan warna cerah membuat para siswa tertarik dan tidak bosan dalam mempelajari Bahasa Mandarin. Hal tersebut senada dengan pernyataan Alperi (2019:103) tentang kelebihan teknologi digital antara lain biaya murah, tidak tergantung jarak, memungkinkan pengenalan layanan-layanan baru, kapasitas besar, fleksibilitas keuntungan, lebih mudah diakses, dan efisiensi waktu. Selain itu, hal tersebut juga senada dengan kelebihan bahan ajar yang disebutkan Erviana (2017) yaitu kelebihan kegunaan (usability).

Para siswa berpendapat bahwa bahan ajar digital ini mudah dioperasikan. Kemudahan tersebut dirasakan saat siswa mengoperasikan bahan ajar baik di layar genggam maupun di laptop, saat membuka link youtube. Hal tersebut diungkapkan oleh para siswa karena bahan ajar menggunakan aplikasi yang mudah dioperasikan serta menggunakan teknologi yang menyesuaikan dengan perkembangan zaman. Hal tersebut sesuai dengan pendapat Erviana (2017) tentang kelebihan bahan ajar yaitu kemudahan penggunaan (ease of use) dan kemudahan baca (readability). Sementara itu, Darmawan (2015) menyebutkan bahwa media informasi dan Teknologi (IT) dapat mempermudah dan mempercepat proses pembelajaran.

Materi yang disajikan pada bahan ajar digital Bahasa Mandarin 流利说汉语[liúli shuo hànyǔ] dianggap sangat jelas dan terjabar karena telah dibahas secara detail, terdapat contoh suara, gambar, video, terdapat bagian yufa, materinya mudah dipahami, lengkap, serta tersedia keterampilan menyimak, berbicara, membaca dan menulis. Hal tersebut membuat siswa merasa materi yang disediakan dalam bahan ajar digital Bahasa Mandarin 流利说汉语[liúlì shuō hànyǔ] membantu para siswa untuk memahami materi pembelajaran. Erviana (2017) menyebutkan salah satu kelebihan bahan ajar yaitu kelebihan kegunaan (usability) dimana bahan ajar digital berfungsi untuk menyampaikan informasi atau ilmu pengetahuan kepada pembaca yang dapat digunakan kapan saja, baik saat proses pembelajaran atau diluar proses pembelajaran.

Bahan ajar digital Bahasa Mandarin 流利说汉语[liúlì shuō hànyǔ] memiliki berbagai macam komponen didalamnya seperti, video youtube, rekaman suara, bagian materi, latihan, dll. Dari bagian-bagian tersebut, siswa menyukai bagian tutorial penulisan hanzi, penjelasan yang 
menyediakan link youtube, penjelasan yang menyediakan rekaman suara, penjelasan yang langsung akses ke sumber materi. Salah satu siswa menambahkan alasan mengapa siswa menyukai bagian tersebut karena saat ini masih jarang sekali ada bahan ajar yang seperti itu. Alperi (2019: 104) menyebutkan keuntungan dari buku digital dengan format epub salah satunya yaitu banyak aplikasi pembaca epub di berbagai perangkat, dan dukungan untuk audio, video, xml, xhtml, html5 dan css.

Penerapan bahan ajar digital Bahasa Mandarin “流利说汉语” [liúlì shuō hànyǔu pada siswa kelas X lintas minat SMAN 2 Malang dan guru Bahasa Mandarin dapat dikatakan mendapat respon positif. Hal tersebut tampak pada jawaban guru maupun siswa. Dari empat pertanyaan yang diajukan oleh peneliti kepada guru Bahasa Mandarin dan enam pertanyaan kepada siswa, seluruh pertanyaan tersebut mendapat jawaban yang baik. Hal tersebut sesuai dengan pernyataan Husna (2018) bahwa sikap yang muncul positif yakni cenderung menyenangi, mendekati dan mengharapkan suatu objek, seseorang disebut mempunyai respon positif dilihat dari tahap kognisi, afeksi, dan psikomotorik. Guru maupun siswa menyukai bahan ajar tersebut dan tertarik belajar serta mengajarkan Bahasa Mandarin menggunakan bahan ajar tersebut. Pernyataan tersebut sesuai dengan pendapat Alperi (2019: 104) bahwa Buku digital lebih praktis dan ekonomis.

\section{KESIMPULAN}

Berdasarkan kajian analisis yang telah dilakukan pada tahap hasil dan pembahasan, maka dapat diambil kesimpulan bahwa implementasi bahan ajar digital bahasa Mandarin “流利说汉语” [liúlì shuō hànyǔ] pada pembelajaran Bahasa Mandarin kelas X di SMAN 2 Malang mendapat respon positif dari siswa maupun dari guru pengampu Bahasa Mandarin. Hal tersebut terlihat pada hasil jawaban pada lembar angket yang telah dikumpulkan. Saran yang diberikan oleh peneliti untuk pengembang selanjutnya yaitu agar mengembangkan bahan ajar digital dengan materi lainnya yang sesuai dengan kurikulum Bahasa Mandarin yang berlaku.

\section{UCAPAN TERIMA KASIH}

Penelitian ini dibiayai oleh Hibah Penerimaan Negara Bukan Pajak (PNBP)/Hibah Penerimaan Non-Pajak Fakultas Sastra Universitas Negeri Malang. Peneliti mengucapkan terima kasih kepada seluruh tim peneliti yang telah memberikan tenaga, waktu, dan pikiran dalam seluruh proses penelitian. Tidak lupa ucapan terima kasih kepada pihak-pihak yang telah membantu penelitian ini serta mendukung dari awal proses penelitian ini sampai akhir penelitian.

\section{DAFTAR PUSTAKA}

Abidin, Y. (2016). Desain Sistem Pembelajaran dalam Konteks Kurikulum 2013. Bandung: Refika Aditama.

Alperi, Muzanip .2019. Peran Bahan Ajar Digital Sigil Dalam Mempersiapkan Kemandirian Belajar Peserta Didik. Jurnal Teknodik. Vol. 23, No. 2. (Online). (http://118.98.221.148/index.php/jurnalteknodik/article/view/479/431) diakses pada 2 April 2021. 
Andi Prastowo. (2011). Panduan Kreatif Membuat Bahan Ajar Inovatif. Yogyakarta: Diva sPress

Azis, Hasbi. 2019. Pengembangan Bahan Ajar Fisika. https://www.academia.edu/

Baroroh, Mashnuatul. 2013. Peningkatan Minat Belajar Siswa Pada Pembelajaran Bahasa Arab Materi Istima Melalui Media Berbasis Ict Kelas Iv Mi Maarif Pademonegoro Sidoarjo. Skripsi. (Online), (http://digilib.uinsby.ac.id/10907/) diakses pada 1 Maret 2021

Chaplin, J. P. (2011). Kamus lengkap psikologi. Jakarta: PT. Raja Grafindo Persada. Barsowi dan Suwandi, 2008)

Darmawan D. dan Bariyah SH. 2015. Pengembangan E-Learning Berbasis Moodle dan Facebook pada Mata Pelajaran TIK.Jurnal Teknodik, Edisi Tahun 2015,227-240. (Online), (https://jurnalteknodik.kemdikbud.go.id/index.php/jurnalteknodik/article/view/129)

diakses pada 2 April 2021

Erviana, Nena. 2017. Pengembangan Bahan Ajar Digital Mata Pelajaran Pemrograman Web Bermuatan Project Based Learning Untuk Menumbuhkan Kreatifitas Siswa Kelas X Program Keahlian Rekayasa Perangkat Lunak Di SMK Negeri 2 Singosari. Skripsi Tidak Diterbitkan. Malang: Fakultas Sastra Universitas Negeri Malang.

Fadillah, M. 2014. Implementasi Kurikulum 2013 Dalam Pembelajaran SD/MI, SD/MTS, dan SMA/MA. Yogyakarta : Ar-Ruzz

Haryanti, Sri. 2013. Analisis Kesesuaian Penggunaan Bahan Ajar Bahasa Mandarin Sekolah Menengah Umum dengan Ketetapan Badan Standar Nasional Pendidikan. Jurnal Humaniora, Vol. 4, No. 1. (Online), (https://journal.binus.ac.id/) diakses pada 2 Maret 2021.

Husna, Asmaul. (2018). Respon wali murid terhadap peran muhammadiyah dalam mengembangkan pendidikan. Universitas Riau JOM FISIP 5(1). https://media.neliti.com/media/publications/205007-respon-wali-murid-terhadap-peranmuhamma.pdf, diakses pada tanggal 27 Oktober 2020.

Kemendikbud. 2012. Kurikulum 2013. Jakarta: Kemendikbud

Mardasari, Octi Rjeky. 2019. Relevansi Buku Ajar “高级汉语”( Gaoji Hanyu) Dengan Kurikulum 2013. Malang: Universitas Negeri Malang.

Nafidah, Rahmatun dan Suratman, Bambang. 2021. Pengembangan Bahan Ajar Digital Interaktif Berbantuan Adobe Flash Pada Mata Pelajaran Korespondensi Kelas X OTKP di SMK YPM 3 Taman. Jurnal Pendidikan Administrasi Perkantoran, Vol. 9, No. 1. (Online), (https://journal.unesa.ac.id/index.php/jpap/article/view/8764/0) diakses pada 30 April 2021. 
JURNAL ILMIAH BAHASA DAN SASTRA

Volume 8 Nomor 2 Tahun 2021

eISSN : 25494155 - pISSN : 23557083

Prastowo, A. 2012. Panduan Kreatif Membuat Bahan Ajar Inovatif. Jogjakarta: Diva Press.

韩明.2012. 东南亚汉语教材使用现状调查研究. 国家教育行政学院学报 